\title{
In vitro and in vivo characterisation of a novel peptide delivery system: amphiphilic polyelectrolyte-salmon calcitonin nanocomplexes.
}

CHENG, W.-P., THOMPSON, C., RYAN, S.M., AGUIRRE, T., TETLEY, L. and BRAYDEN, D.J. 


\title{
In vitro and in vivo characterisation of a novel peptide
}

\author{
delivery system: amphiphilic polyelectrolyte-salmon
}

\section{calcitonin nanocomplexes}

Woei-Ping Cheng a , Colin Thompson ${ }^{\mathrm{b}}$, Sinéad M. Ryan ${ }^{\mathrm{c}}$, Tanira Aguirre ${ }^{\mathrm{c}}$,
Laurence Tetley ${ }^{\mathrm{d}}$, David J. Brayden * c

a School of Pharmacy, University of Hertfordshire, College Lane Hatfield AL10 $9 \mathrm{AB}, \mathrm{UK}$,

${ }^{\mathrm{b}}$ School of Pharmacy and Life Sciences, The Robert Gordon University, Schoolhill, Aberdeen AB10 1FR, UK

${ }^{\mathrm{c}}$ School of Veterinary Medicine and Conway Institute, University College Dublin, Dublin 4, Ireland

${ }^{\mathrm{d}}$ Division of Infection \& Immunity, IBLS, Integrated Microscopy Facility, Joseph Black Building, University of Glasgow, Glasgow G12 8QQ, UK

*Author for correspondence:

Email: david.brayden@ucd.ie

Tel.: +353 (1) 7166013

Fax: +353 (1) 7166219 


\begin{abstract}
The cationic peptide, salmon calcitonin ( $\mathrm{sCT}$ ) was complexed with the cationic amphiphilic polyelectrolyte, poly(allyl)amine, grafted with palmitoyl and quaternary ammonium moieties at $\mathrm{pH} 5.0$ and 7.4 to yield particulates (sCT-QPa). The complexes were approximately $200 \mathrm{~nm}$ in diameter, had zeta potentials ranging from +20 to $+50 \mathrm{mV}$, and had narrow polydispersity indices (PDIs). Differential scanning calorimeter revealed the presence of an interaction between sCT and $\mathrm{QPa}$ in the complexes. Electron microscopy confirmed the zeta-size data and revealed a vesicular bilayer structure with an aqueous core. Tyrosine- and Nile red fluorescence indicated that the complexes retained gross physical stability for up to 7 days, but that the $\mathrm{pH} 5.0$ complexes were more stable. The complexes were more resistant to peptidases, serum and liver homogenates compared to free $\mathrm{sCT}$. In vitro bioactivity was measured by cAMP production in T47D cells and the complexes had EC50 values in the $\mathrm{nM}$ range. While free sCT was unable to generate cAMP following storage for 7 days, the complexes retained approximately $33 \%$ activity. When the complexes were injected intravenously to rats, free and complexed sCT (pH 5.0 and 7.4) but not QPa reduced serum calcium over $120 \mathrm{~min}$. Free and complexed-sCT but not QPa also reduced serum calcium over 240 min following intra-jejunal administration. In conclusion, sCT-QPa nanocomplexes have been synthesised that are stable, bioactive and resistant to a range of peptidases. These enhanced features suggest that they may have the potential for improved efficacy when formulated for injected and oral delivery.
\end{abstract}

\title{
Key words:
}

Salmon calcitonin, poly(allyl)amine, amphiphilic polymers, oral peptide delivery, peptidase inhibition. 


\section{Introduction}

Since complexation of bovine serum albumen (BSA) with a synthetic polyelectrolyte was first described [1], such complexes have been used widely in the food and biotechnology industry. Examples include stabilisation of enzymes for biosensors [2], and for developing protein separation methods [3]. Use of polyelectrolytes for non-injected peptide and protein delivery resulted in formulation of positively-charged chitosan nanocomplexes or hydrogels with insulin $[4,5]$, BSA [6], and catalase [7]. The principle mechanism of the non-covalent association is based on electrostatic interaction between positively-charged polymers and negatively-charged proteins to yield a polyelectrolyte complex. Most peptides and proteins however, typically exhibit amphiphilic character due to the presence of multiple hydrophobic and hydrophilic amino acid residues in the primary sequence. Amphiphilic polymers may have unique potential in peptide delivery due to their ability to interact with such peptides via both electrostatic and hydrophobic association. However, to our knowledge only a few groups have studied them for delivery of therapeutic peptides including insulin [8] and salmon calcitonin $(\mathrm{sCT})[9]$.

Our previous work demonstrated the use of novel comb-shaped amphiphilic polyelectrolytes based on polyallylamine (PAA) designed for oral delivery of insulin [10-12]. PAA protected insulin from in vitro gastrointestinal enzymatic degradation by pepsin, and trypsin to an extent [12], due to the nature of the hydrophobic pendant group and the presence of quaternary ammonium moieties [10]. Among the amphiphilic polyelectrolytes examined, the most promising analogue was PAA grafted with a combination of palmitoyl $(4.2 \%$ mole $)$ and quaternary ammonium moieties (QPa, 73\% mole). Proteins and peptides can be anionic or 
cationic at physiological $\mathrm{pH}$, depending on their isoelectric point (PI) and the $\mathrm{pH}$ of the compartment solution. Therefore, it is important to assess the ability of amphiphilic polyelectrolytes to deliver both cationic and anionic peptides. To date, most research has focussed on complexation between polymers and peptides of opposite charge. There are reports which suggest that polyelectrolyte complexation can indeed be formed with the same overall charge due to the presence of localized patches of opposite charge on the peptide surface [13], or due to hydrophobic interactions or hydrogen bonding between polymer and peptide [14].

The question for this current study was therefore whether PAA could be complexed with a cationic peptide while retaining physicochemical properties that are compatible with maintenance of bioactivity. $\mathrm{sCT}$ is a 32-residue calcium-regulating peptide hormone produced by parafollicular cells of the thyroid gland, which is used clinically as an adjunct anti-resorptive treatment for post-menopausal osteoporosis and also as a second line treatment for Paget disease [15]. Recent data suggests that $\mathrm{sCT}$ also has potential as a disease-modifying anabolic agent acting on osteoarthritic cartilage to promote collagen and preteoglycan synthesis [16]. Marketed $\mathrm{sCT}$ for osteoporosis is available as a nasal spray or as subcutaneous/intramuscular injections. An oral product would have patient acceptability advantages over both nasal $\mathrm{sCT}$ and oral bisphosphonates, the former prone to occasional local mild irritation due to the presence of permeation enhancers [17], while the latter elicits a range of intestinal side-effects in a cohort of patients [18]. Anionic sodium tripolyphosphate was recently complexed to sCT to form an ionic complex via electrostatic attraction and it had some oral efficacy in rats [19]. Here, complexation between the cationic $\mathrm{QPa}$ and cationic $\mathrm{sCT}$ was achieved in $\mathrm{pH} 5.0$ and $\mathrm{pH} 7.4$ buffers and the resulting nanocomplexes yielded positive outcomes from the standpoint of 
physicochemical properties, resistance to enzymatic degradation, in vitro $\mathrm{sCT}$ bioactivity as well as in vivo hypocalcaemic efficacy in rats. 


\section{Materials and Methods}

\subsection{Materials}

Poly(allylamine hydrochloride) (PAA) $(\mathrm{Mw}=15 \mathrm{kDa})$, palmitic acid-Nhydroxysuccinimide ester (98\%), sodium acetate, tris(hydroxymethyl) aminomethane (Tris) ( $\geq 99 \%$ ) and Nile Red were all purchased from Sigma-Aldrich, UK. All solvents (HPLC grade) and glacial acetic acid were purchased from Fisher Scientific Chemicals, UK. sCT was purchased from PolyPeptide Laboratories (Denmark). The Parameter ${ }^{\mathrm{TM}}$ cAMP (EIA) kit was purchased from R\&D systems, UK. Tissue culture reagents were obtained from BioSciences, Ireland. All other chemicals were of reagent grade. T47D cells were purchased from LGC Standards, UK.

\subsection{Synthesis of $Q P a$}

In accordance with [10], PAA was reacted with palmitic acid-N-hydroxysuccinimide ester, based on molar feeds of 1:0.025 (PAA monomer: palmitoyl group) to obtain PAA grafted with palmitoyl-pendant groups $(\mathrm{Pa})$. Quaternisation $(\mathrm{Q})$ was carried out by reacting $\mathrm{Pa}$ with over a 1000 molar excess of methyl iodide to obtain quaternary ammonium compounds, QPa (Fig. 1). The novel amphiphilic polymers were characterised by elemental analysis and ${ }^{1} \mathrm{H}$ NMR and the results confirmed $4.2 \%$ mole palmitoylation and the palmotoyl graft $[10,11]$.

\subsection{Preparation of $s C T-Q P a$ nanocomplexes}

Complex preparation of sCT with QPa was carried out similar to our previous method using insulin [11]. Two buffers, Tris ( $\mathrm{pH}$ 7.4) and acetate buffer ( $\mathrm{pH} 5.0)$ were used to separately prepare sCT-QPa complexes. Tris buffer was made up of $0.1 \mathrm{M}$ Tris: $0.01 \mathrm{M} \mathrm{HCl}(87: 13 \%$ 
$(\mathrm{v} / \mathrm{v}))$, and the acetate buffer was composed of sodium acetate $\left(0.871 \mathrm{gL}^{-1}\right)$ and glacial acetic acid $\left(0.216 \mathrm{gL}^{-1}\right)$. Solutions $\left(4 \mathrm{mgmL}^{-1}\right)$ were prepared by sonicating the polymer in either buffer using a Soniprep $150 \circledR$ sonicator (MSE Ltd., UK) for 5 min at the maximum amplitude. sCT stock solutions $\left(2 \mathrm{mgmL}^{-1}\right)$ were prepared also in both buffers using gentle magnetic stirring. Equal volumes (2 $\mathrm{mL}$ each) of QPa and $\mathrm{sCT}$ solutions were added together and the sCTQPa complexes were formed spontaneously after mixing. The solutions were then left at room temperature for $120 \mathrm{~min}$ and the $\mathrm{pH}$ values were re-checked before characterisation as described in Section 2.4 and 2.5.

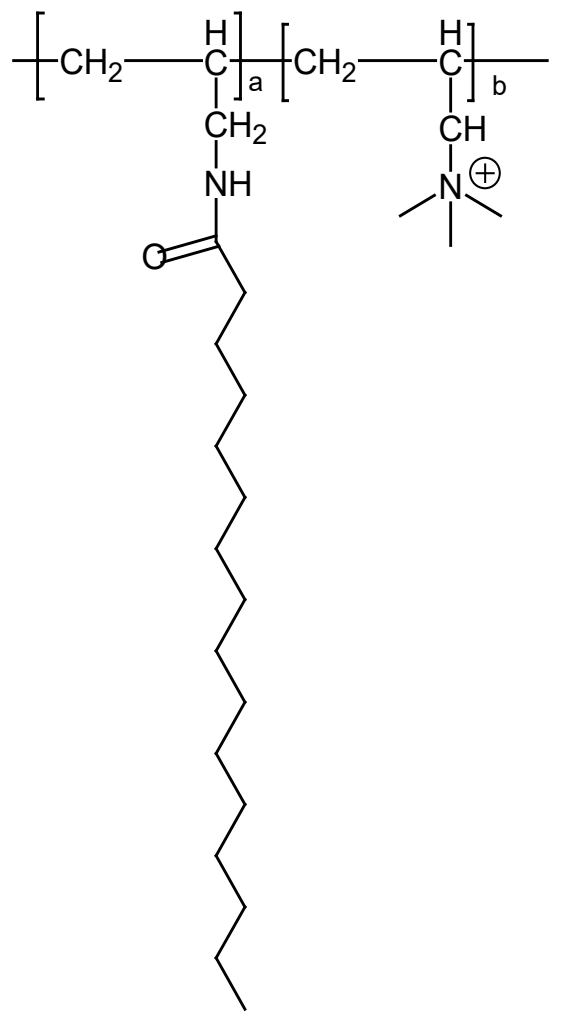

Fig. 1. Chemical structure of quaternary ammonium palmitoyl polyallylamine (QPa).

\subsection{Characterization of polymer, $s C T$ complexes}

2.4.1. Differential scanning calorimetry (DSC) 
QPa, sCT and QPa-sCT complexes $\left(2: 1 \mathrm{mgmL}^{-1}\right)$ were freeze dried in a VirTis adVantage freeze drier (Biopharma Process Systems, UK) in both Tris and acetate buffers. Samples (1-2 mg) were then heated from $0^{\circ} \mathrm{C}$ to $300^{\circ} \mathrm{C}$ at $20^{\circ} \mathrm{Cmin}^{-1}$ in a Q100 differential scanning calorimeter (TA instruments, UK), precalibrated with indium. The above experiment was repeated using sCT as received from the supplier.

\subsubsection{UV Absorbance}

The turbidity of QPa, sCT and sCT-QPa complexes were tested at day 0, 1 and 7 after preparation by taking absorbance readings at $350 \mathrm{~nm}$ using a Biomate $5 \mathrm{UV}$ spectrophotometer (Thermo Spectronic, England) with a $1 \mathrm{~cm}$ quartz cuvette. Absorbance values were determined after blanking the spectrophotometer with the buffer used to prepare sCT/QPa samples. The samples were maintained at room temperature in the dark over the 7 days.

\subsubsection{Intrinsic tyrosine fluorescence}

The fluorescence of the tyrosine residues within $\mathrm{sCT}$ was measured using a LS 55 luminescence spectrometer (Perkin Elmer, USA) according to [20]. The changes of the emission spectra of the intrinsic tyrosine residues within the $\mathrm{SCT}$ give an indication of the physical stability of sCT. Emission spectra were recorded using the supplied software over an emission wavelength range of 290 to $400 \mathrm{~nm}$ after excitation at $274 \mathrm{~nm}$ using slit widths of $3 \mathrm{~nm}$. An average of three scans was taken for each sample. Intensity values at peak emission wavelength were noted at days 0,1 and 7 after the formation of sCT-QPa complexes and compared to free sCT.

\subsubsection{Nile red fluorescence}


Since intrinsic tyrosine fluorescence measurement may be less sensitive in detecting sCT aggregation compared to extrinsic fluorescence, extrinsic Nile red fluorescence was also used to determine sCT stability. QPa, sCT and sCT-QPa complexes were spiked with a $0.10 \mathrm{mM}$ solution of Nile Red in ethanol ( $40 \mu \mathrm{L}$ in $4 \mathrm{~mL}, \mathrm{n}=3$ ) [20]. Controls consisting of each buffer $(4 \mathrm{~mL})$ were also spiked with Nile red. All samples were left in the dark at room temperature for the duration of the study. The emission intensities of the Nile red-spiked samples and nile red alone in each buffer were recorded between wavelengths of $600-700 \mathrm{~nm}$ following initial excitation at $575 \mathrm{~nm}$ at a slit width of $7.5 \mathrm{~nm}$. Peak intensities were measured using a LS 55 luminescence spectrometer (Perkin Elmer, USA) at days 0, 1 and 7 after sample preparation with an average of three scans of each sample.

\subsubsection{Particle size analysis: photon correlation spectroscopy (PCS)}

Hydrodynamic diameters and polydispersity indices (PDI) of polymer, sCT and sCT-QPa complexes in both buffers were determined using photon correlation spectroscopy (PCS) (Zetasizer Nano-ZS, Malvern Instruments, UK) at $25^{\circ} \mathrm{C}$. Analysis was carried out at days 0,1 and 7 after preparation.

\subsubsection{Zeta potentials}

The zeta potential of QPa, sCT and sCT-QPa complexes were analysed using PCS (Zetasizer Nano-ZS, Malvern Instruments, UK) at days 0 and 7 after preparation. Prior to measurement, $-50 \mathrm{mV}$ standards (Malvern Instruments, UK) were analysed; the data obtained agreed with that stated by the manufacturer. 


\subsubsection{Transmission electron microscopy (TEM)}

Formvar/carbon-coated 200 mesh copper grids were glow-discharged and freshlyprepared complex solutions were dried to form a thin layer onto the hydrophilic support film. 1\% aqueous methylamine vanadate (Nanovan ${ }^{\circledR}$; Nanoprobes, Stony Brook, NY, USA) stain was applied and the mixture air-dried. The negatively-stained complexes were imaged with a LEO 912 energy filtering transmission electron microscope, at 80 or $100 \mathrm{kV}$.

\subsection{In vitro and in vivo characterisation of $s C T-Q P a$ complexes}

\subsubsection{In vitro bioactivity: Intracellular cAMP elevation by $s C T$ and complexes in $T 47 D$ cells}

cAMP-secreting activities of sCT and complexes were assessed using a T47D (human breast cancer cells) in vitro bioassay [21]. Human breast cancer cells (T47D) cells over-expresses calcitonin receptors and resulting in intracellular cAMP release upon activation by sCT. T47D cells were maintained in RPMI-1640 culture medium (Gibco) containing 1\% penicillinstreptomycin (Gibco), 10\% fetal bovine serum (Gibco) and insulin ( $0.2 \mathrm{IU} / \mathrm{ml})$. The cells were plated at an initial density of $1.0 \times 10^{5}$ cells/well and incubated in a $95 \%$ air: $5 \% \mathrm{CO}_{2}$ atmosphere at $37^{\circ} \mathrm{C}$ for 24 hours. Media was replaced with serum-free media and incubated for a further 24 hours. After washing with Hank's balanced salt solution (HBSS) (Sigma), cells were pre-incubated with the serum free media, supplemented with $0.2 \mathrm{mM} 3$-isobutyl-1-methylxanthine (IBMX) at $37^{\circ} \mathrm{C}$ for $120 \mathrm{~min}$. The cells were then incubated with different concentrations of freshly prepared (day 0) $\mathrm{sCT}$ and $\mathrm{sCT}-\mathrm{QPa}(\mathrm{pH} 5.0$ and 7.4) complexes at 37 ${ }^{\circ} \mathrm{C}$ for $15 \mathrm{~min}$. After removing the supernatants, intracellular cAMP was extracted from the cells by lysis and measured by ELISA (R\&D Systems, UK). Concentration-response curves were also 
carried out on samples from the same stocks after 7 days (day 7). The concentrations of sCT in the complexes were directly comparable with free sCT.

\subsubsection{Intestinal enzyme metabolism}

sCT-QP complexes were incubated with intestinal enzymes in transport buffer according to our previous description [22]: TPCK (N-p-tosyl-Lphenylalanine chloromethyl ketone)-treated trypsin $(0.5 \mu \mathrm{M})$, TLCK (1- chloro-3-tosylamido-7-amino-2-heptanone)-treated chymotrypsin $(0.1 \mu \mathrm{M})$ and elastase $(0.48 \mu \mathrm{M})$. The concentrations of enzymes used were similar to those present in the gastrointestinal tract. Enzymes and substrates were incubated separately at $37^{\circ} \mathrm{C}$ for $15 \mathrm{~min}$, followed by co-incubation for $0,15,30,45,60$ and $90 \mathrm{~min}$. Samples were analysed for the capacity to induce cAMP production in T47D cells. Rate constants and half lives for formulations were calculated by assuming first order kinetics.

\subsubsection{Hypocalcaemia of $s C T-Q P$ a formulations in rats: intravenous and intra-jejunal administration}

Fasted male Wistar rats (300-350g) were initially anesthetised using intra-peritoneal (i.p.) injection of ketamine $(75 \mathrm{mg} / \mathrm{kg})$ and xylazine $(10 \mathrm{mg} / \mathrm{kg})$. Anaesthesia was maintained with isoflurane gas at the rate of $1.5 \mathrm{~L} /$ min mixed with $\mathrm{O}_{2}(1 \mathrm{~L} / \mathrm{min})$ through a gas mask.

Rats were randomly divided into groups and were injected via the tail vein with $40 \mu \mathrm{g} / \mathrm{kg}(200$ $\mathrm{IU} / \mathrm{mL} / \mathrm{kg}$ ) sCT from each formulation: sCT, QPa, sCT-QPa, each prepared at both $\mathrm{pH} 5.0$ and 7.4. Serum samples were obtained directly from the heart at time 0 and then at $15,30,60$ and 120 min after i.v. injection. Intra-jejunal (i.j.) administration was also carried out in separate studies based on previous methods [23]. The proximal jejunum from anaesthetised rats were exposed after a midline laparotomy. $15 \mathrm{~cm}$ of jejunum was isolated by tighten the extremities up 
with silk, taking care to avoid damage to blood vessels. Solutions containing $0.1 \mathrm{mg} / \mathrm{ml} \mathrm{sCT}$ ( 500 $\mathrm{IU} / \mathrm{ml}$ ) at the volume of $1 \mathrm{ml} / 300 \mathrm{~g}$ of bodyweight were instilled into the surgically exposed jejunal segments. The i.j. study had same design as for intravenous (i.v.) study, except that samples were withdrawn up to $240 \mathrm{~min}$. Serum samples were analysed for calcium using a Randox Laboratory clinical chemistry colorimetric analyzer at a wavelength of $612 \mathrm{~nm}$ [22]. Animal experimental procedures adhered to the Principles of the Laboratory Animal Care, were performed in compliance with the Irish Department of Health and Children animal licence number, B100/4193, and were approved by the UCD Animal Research Ethics Sub-Committee.

\subsection{Statistical analysis}

R Statistical Language was used to perform non-linear regression, t-tests, Tukey-HSD post hoc ANOVA comparison and to construct confidence intervals. $\mathrm{P}<0.05$ was designated as the level of significance. 


\section{Results}

\subsection{Characterisation of $s C T-Q P$ a complexes}

\subsubsection{DSC}

From the acetate samples, complexation led to a change in the DSC profile compared to free sCT and QPa alone. Free sCT had two endotherms, a broad endotherm at $70^{\circ} \mathrm{C}$ and another sharp endotherm at $130^{\circ} \mathrm{C}$ while QPa had endotherms at 90 and $240^{\circ} \mathrm{C}$ (Fig $\left.2 \mathrm{~A}\right)$. Upon complexation, the endotherms observed for free $\mathrm{sCT}$ had disappeared and a broad thermogram occurring at $120^{\circ} \mathrm{C}$ was observed. This result is consistent with our findings with the QPa-insulin complexes and other polyelectrolyte complexes $[11,19]$. The physical-chemical interaction between sCT and QPa had resulted in the disappearance of free sCT endotherms and the shift of QPa endotherm to a higher temperature.

In regards the Tris samples, the picture is more complex. QPa and the complex thermal profiles seemed to be very similar in acetate buffer, but not so in Tris. There was a large endotherm at $150^{\circ} \mathrm{C}$ in the QPa Tris buffer sample that was not present in the acetate buffer sample, which may be due to the Tris itself having recrystallised on freeze drying (Fig 2B). The absence of this large peak in the thermal profile of QPa freeze-dried in water confirmed this hypothesis (data not shown). Complexation of QPa with sCT resulted in the disappearance of this peak and the small endotherms in the free $\mathrm{sCT}$ samples between $100-150^{\circ} \mathrm{C}$, suggesting the presence of an interaction between $\mathrm{QPa}$ and $\mathrm{sCT}$. However, the multiple endotherms in the $\mathrm{sCT}$ and QPa samples between $225-250^{\circ} \mathrm{C}$ were still present in the complex sample. This suggests possible degradation of $\mathrm{QPa}$ and/or denaturation of $\mathrm{sCT}$ in the complex at a high temperature. In Fig 2C, sCT as received from the commercial supplier had a different thermal profile compared to the free sCT freeze-dried in acetate or Tris buffer. The differences observed may 
suggest that there is an interaction between $\mathrm{SCT}$ and the buffer. This may explain the lack of stability in Tris compared to acetate buffer, which was shown in our result (section 3.1.2 and 3.1.3) as well as others [20]. Heat Flow (W/g)
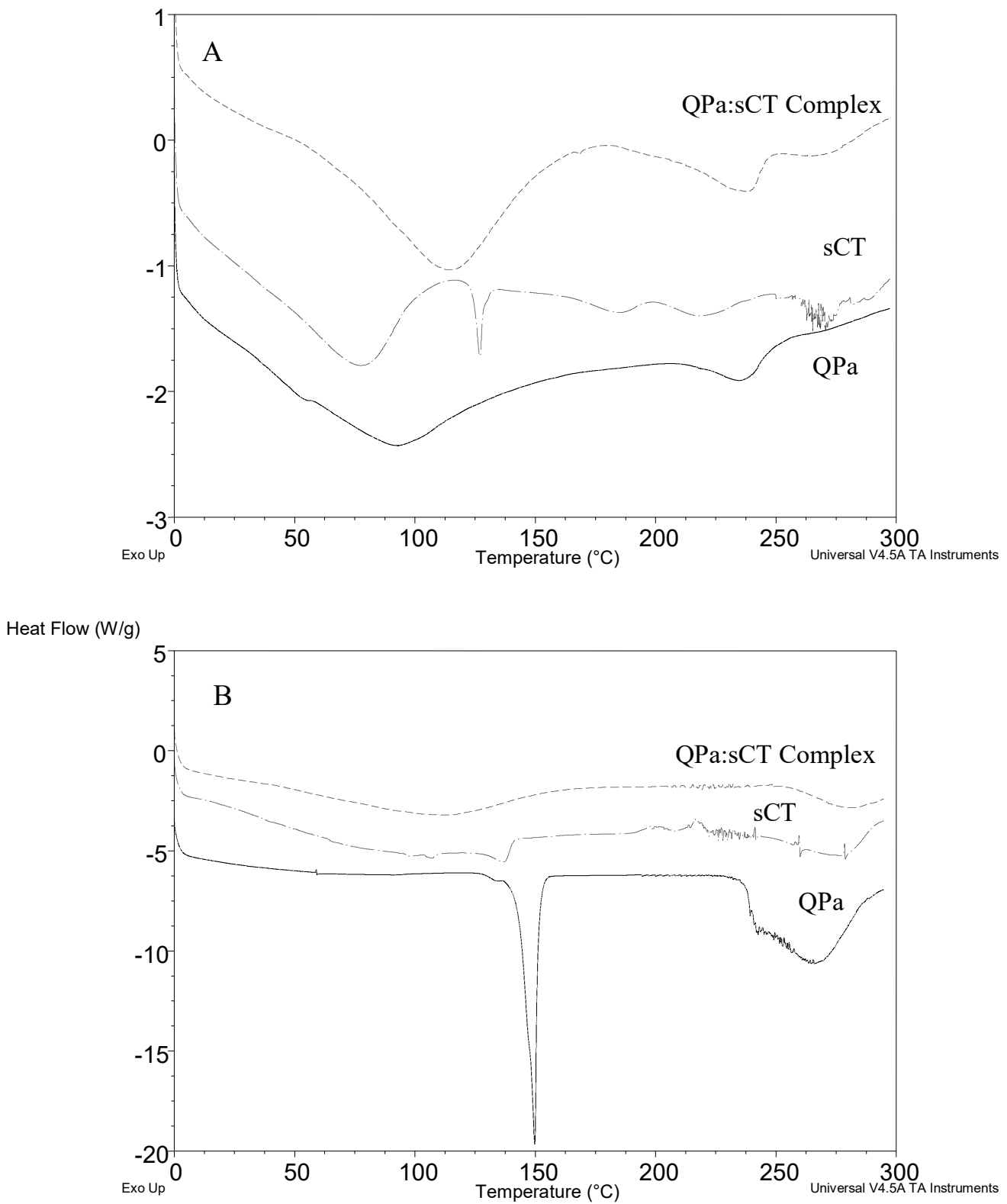


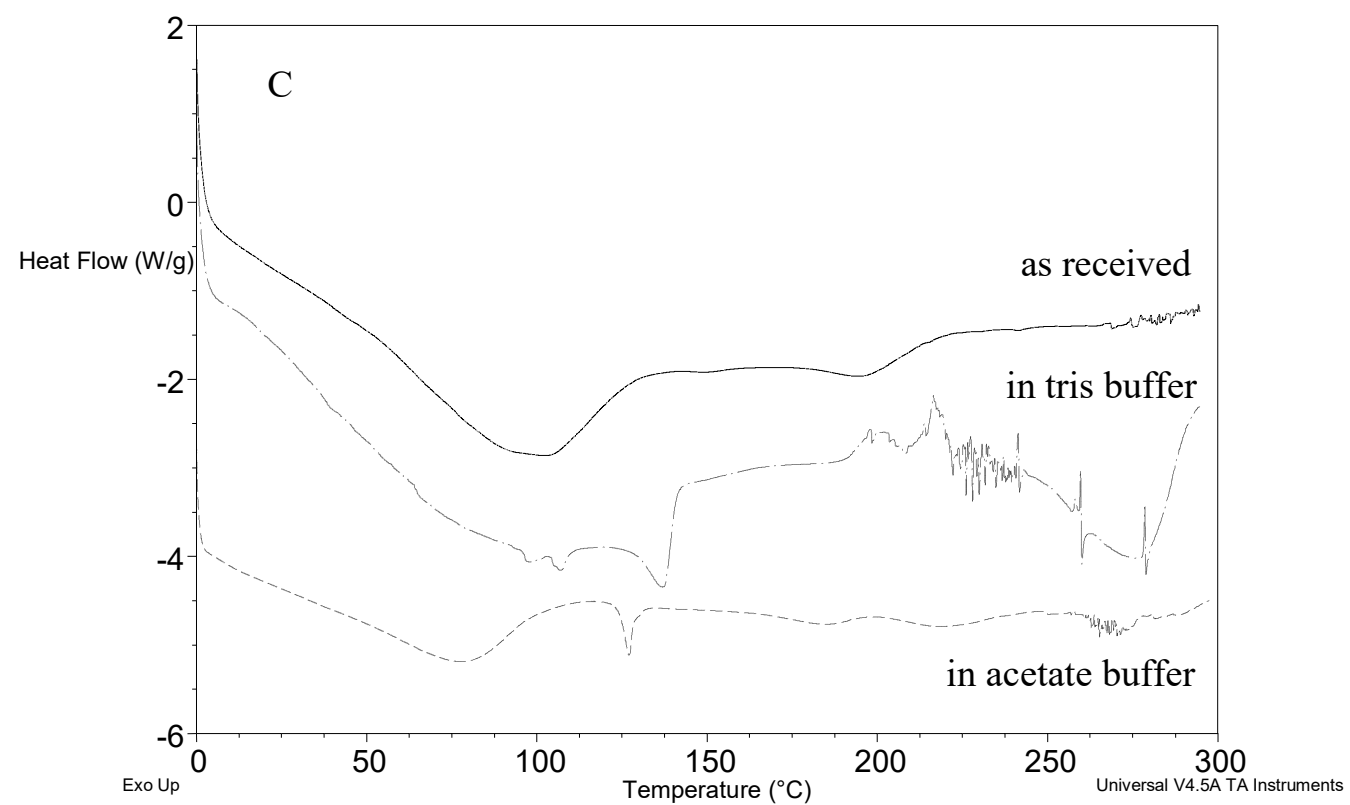

Figure 2. DSC profile of (A) Freeze dried QPa, sCT and QPa:sCT complex $\left(2: 1 \mathrm{mgmL}^{-1}\right)$ in acetate buffer. (B) Freeze dried QPa, sCT and QPa:sCT complex $\left(2: 1 \mathrm{mgmL}^{-1}\right)$ in Tris buffer. (C) freeze-dried $\mathrm{sCT}$ in acetate/ Tris buffer or as received.

\subsubsection{PCS, zeta potential and UV spectroscopy}

Samples were analysed for their hydrodynamic size, PDI, zeta potential and UV absorbance at day 0 and / or day 1 and at day 7 after preparation (Table 1). Samples were deemed stable at a gross level if absorbance readings remained below an O.D. value of 0.0-0.035 [20]. sCT samples were stable at day 0 , but by day 7 absorbance values had risen above 0.035 in both buffers. This was particularly marked for samples at $\mathrm{pH} 7.4(\mathrm{~A}=0.269)$ compared to $\mathrm{pH} 5$ $(\mathrm{A}=0.044)$ suggesting that $\mathrm{sCT}$ was less stable at $\mathrm{pH}$ 7.4. The absorbance values for $\mathrm{QPa}$ alone were always above 0.035 as they were not completely clear. This meant that complex samples were also above 0.035. Again, however, samples appeared more stable at $\mathrm{pH} 5$ than $\mathrm{pH} 7.4$, 
given the smaller changes in absorbance at day 7; absorbance increased from 0.054 to 0.071 and from 0.053 to 0.253 at $\mathrm{pH} 5$ and 7.4 , respectively (Table 1). The precipitation observed for both sCT and the complex at $\mathrm{pH} 7.4$ at day 7 would suggest that the complex became unstable at this $\mathrm{pH}$, although precipitation from the complex appeared to be less than from free sCT. It would have been expected that if the $\mathrm{sCT}$ and QPa were not interacting with each other, two distinct size populations would be present in the complex samples which would be indicated by higher size and PDI values and multiple peaks in the size distribution graph. However, all complex samples over 7 days had diameter and PDI values of less than $230 \mathrm{~nm}$ and 0.3 respectively (Table 1). In addition, one single peak was obtained in the size distribution graphs (Fig 2A, B), suggesting that complexation between $\mathrm{sCT}$ and $\mathrm{QPa}$ led to formation of compact nanoaggregates with relatively narrow size distribution at either $\mathrm{pH}$. This suggests the absence of free sCT in the complexes, consistent with previous SEC-HPLC data from insulin-QPa complexes $[11,12]$. Diameters and PDI values for sCT-QPa complexes were comparable to those of QPa, but differed markedly from those of sCT. Free sCT had a substantially higher hydrodynamic size ranging from $458 \mathrm{~nm}$ to $2 \mu \mathrm{m}$ with a PDI of 1 , indicating the presence of particulates of a wide diameter range.

Table 1. Size, zeta potential and absorbance of sCT, sCT-QPa in $\mathrm{pH} 5.0$ or Tris buffers

\begin{tabular}{lccccc}
\hline & Day & $\begin{array}{c}\text { Hydrodynamic } \\
\text { diameter }(\mathbf{n m})\end{array}$ & PDI & Zeta Potential & Absorbance \\
& & & $(\mathbf{m} \boldsymbol{V})$ & $\mathbf{( 3 5 0} \mathbf{n m})$ \\
\hline pH 5.0 & & & & \\
SCT & 0 & $458(141)$ & $0.527(0.093)$ & $39.1(2.54)$ & 0.000 \\
& $2471(934)$ & $1.000(0.000)$ & $20.8(2.70)$ & 0.044 \\
\hline
\end{tabular}




\begin{tabular}{cccccc}
\hline QPa & 0 & $226(2)$ & $0.201(0.015)$ & $52.5(0.92)$ & 0.060 \\
& 7 & $169(4)$ & $0.262(0.003)$ & $52.7(1.17)$ & 0.086 \\
sCT-QPa & 0 & $226(7)$ & $0.232(0.029)$ & $56.6(0.88)$ & 0.054 \\
& 1 & $227(4)$ & $0.228(0.039)$ & $\mathrm{n} / \mathrm{a}$ & 0.059 \\
& 7 & $226(5)$ & $0.209(0.031)$ & $52.1(1.09)$ & 0.071 \\
$\mathbf{p H ~ 7 . 4}$ & & & & & \\
$\mathrm{sCT}$ & 0 & $1827(1279)$ & $0.763(0.191)$ & $17.9(0.78)$ & 0.004 \\
& 7 & $1339(190)$ & $0.802(0.148)$ & $4.5(0.26)$ & 0.269 \\
$\mathrm{QPa}$ & 0 & $204(2)$ & $0.227(0.008)$ & $44.0(2.07)$ & 0.045 \\
& 7 & $128(3)$ & $0.177(0.008)$ & $40.7(3.66)$ & 0.066 \\
$\mathrm{sCT}-\mathrm{QPa}$ & 0 & $197(4)$ & $0.206(0.019)$ & $44.7(0.71)$ & 0.053 \\
& 1 & $194(4)$ & $0.203(0.014)$ & $\mathrm{n} / \mathrm{a}$ & 0.056 \\
& 7 & $225(18)$ & $0.293(0.044)$ & $49.6(2.00)$ & 0.253 \\
\hline
\end{tabular}

$N=3 \pm S D$ for each parameter

All samples had positive zeta potentials ranging from $+21 \mathrm{mV}$ to $+50 \mathrm{mV}$, apart from free $\mathrm{sCT}$ at $\mathrm{pH} 7.4$ at day 7 (Table 1). However, zeta potential values for sCT-QPa complexes were much higher than those of free $\mathrm{sCT}$, but were similar to those of $\mathrm{QPa}$ alone. The zeta potential graphs of complexes in both $\mathrm{pH} 5$ and $\mathrm{pH} 7.4$ buffers showed a single peak appearing at $+57 \mathrm{mV}$ and $+45 \mathrm{mV}$ respectively (Fig 3C, D), and these values were relatively constant after 7 days (Table 1). 

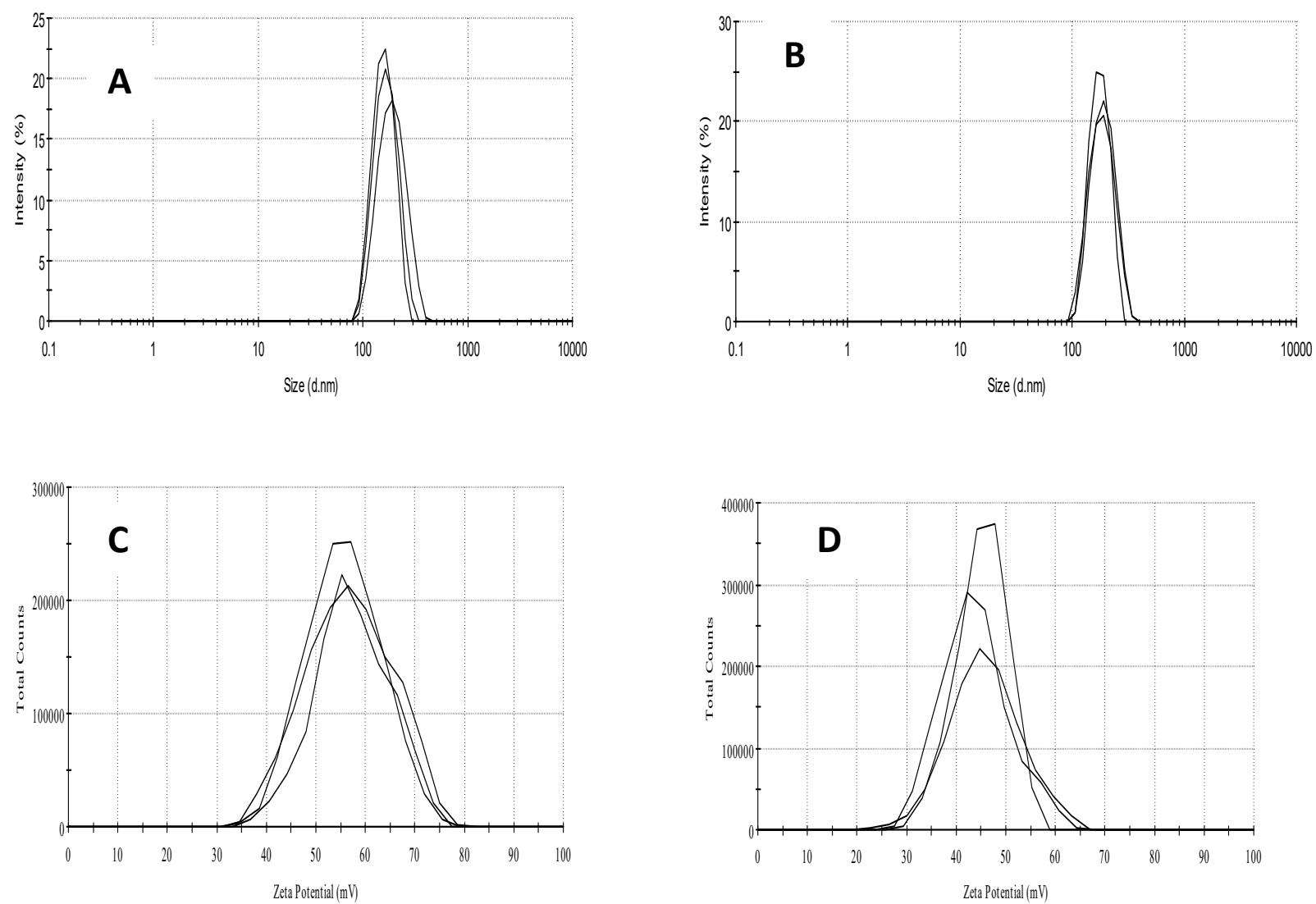

Fig. 3. Size distribution complexes at day 0 at $\mathrm{pH} 5.0$ (A), and $\mathrm{pH} 7.4$ (B). Zeta potential distribution of complexes at day 0 at $\mathrm{pH} 5.0$ (C), and $\mathrm{pH} 7.4$ (D) (triplicate samples).

\subsubsection{Intrinsic tyrosine fluorescence}

Intrinsic tyrosine fluorescence was measured in order to further assess stability of sCT in the complexes. The emission maxima wavelength should not change over time as it is intrinsic to tyrosine unless aggregation or fibril formation occurs. Stable sCT samples should not lose/gain less than $6 \%$ of their peak intensity between days 1 and 7 [24]. There was little change in $\lambda_{\text {emission }}$ and peak intensities for most of the samples over the period (Table 2). Both the sCT-QPa (pH 5.0) complexes and $\mathrm{sCT}$ alone ( $\mathrm{pH} 5.0)$ remained stable and peak intensities only altered by 
$2.6 \%$ and $1.8 \%$, respectively. However the intensity of the sCT-QPa complexes (pH 5.0) fell by $6.5 \%$ and the $\mathrm{sCT}(\mathrm{pH} 7.4)$ fell by $46.6 \%$ at day 7 . This would suggest that $\mathrm{sCT}$ is more stable at $\mathrm{pH} 5$ than $\mathrm{pH} 7.4$ and that complexation has a stabilizing effect on $\mathrm{sCT}$ at $\mathrm{pH} 5.0 . \mathrm{QPa}$ samples had negligible emission changes (data not shown).

\subsubsection{Nile red fluorescence}

sCT samples spiked with Nile red were considered stable if they had emission $\lambda_{\max }$ values $>630 \mathrm{~nm}$ [20]. Small changes in intensity were considered to be due to fluctuations in temperature and binding of Nile red to sample containers. Nile red has an emission maximum of $645 \mathrm{~nm}$ and the fall in maximum to $620-631 \mathrm{~nm}$ is a blue shift [20]. In contrast to tyrosine fluorescence, all Nile red spiked samples underwent shifts in emission $\lambda_{\max }$ (Table 3). Free sCT samples displayed very little fluorescence (Table 3 ) as did Nile red alone in both buffers (data not shown). QPa itself also underwent a blue shift in the $\lambda_{\max }$, while sCT-QPa complexes (pH 5.0 and 7.4) also exhibited blue shifts (Table 3). Given the shift in emission $\lambda_{\max }$ of the complexes to below $630 \mathrm{~nm}$ it would appear that they were less stable than $\mathrm{sCT}$ alone. However this greater shift may be due to the combined effect of QPa and $\mathrm{sCT}$ interaction with Nile red. Therefore shifts in $\lambda_{\max }$ may not be reliable indictors of stability with PEC samples.

Table 2. Tyrosine fluorescence measurements of $\mathrm{sCT}$ and $\mathrm{QPa}, \mathrm{sCT}$ complexes in $\mathrm{pH} 5.0$ and pH 7.4 buffers (triplicate samples).

\section{Intensity at}

\begin{tabular}{cccc} 
pH 5.0 & Day & Emission $\boldsymbol{\lambda}_{\max }(\mathbf{n m})$ & maximum \\
\hline SCT & 0 & 307 & 503 \\
& 1 & 305 & 513
\end{tabular}




\begin{tabular}{|c|c|c|c|}
\hline & 7 & 305 & 504 \\
\hline \multirow[t]{4}{*}{ sCT-QPa } & 0 & 306 & 486 \\
\hline & 1 & 306 & 516 \\
\hline & 7 & 306 & 503 \\
\hline & & & Intensity at \\
\hline pH 7.4 & Day & Emission $\lambda_{\text {max }},(n m)$ & maximum \\
\hline \multirow[t]{3}{*}{$\mathrm{sCT}$} & 0 & 303 & 443 \\
\hline & 1 & 304 & 434 \\
\hline & 7 & 306 & 232 \\
\hline \multirow[t]{3}{*}{ sCT-QPa } & 0 & 305 & 478 \\
\hline & 1 & 304 & 513 \\
\hline & 7 & 305 & 480 \\
\hline
\end{tabular}

Table 3. Fluorescence of Nile red $(1 \mu \mathrm{M})$-spiked sCT, QPa and sCT-QPa QPa complexes and in $\mathrm{pH} 5.0$ and $\mathrm{pH} 7.4$ buffers.

\begin{tabular}{cccc}
\hline pH 5.0 & Day & Emission $\lambda_{\max }(\mathbf{n m})$ & Intensity at maximum \\
\hline sCT & 0 & 630 & 2 \\
& 1 & 637 & 1.5 \\
& 7 & 637 & 1.8 \\
$\mathrm{QPa}$ & 0 & 631 & 232 \\
& 1 & 632 & 203 \\
& 7 & 632 & 144 \\
$\mathrm{sCT}-\mathrm{QPa}$ & 0 & 626 & 172
\end{tabular}




\begin{tabular}{cccc} 
& 1 & 626 & 165 \\
& 7 & 626 & 164 \\
\hline pH7.4 & Day & Emission $\lambda_{\text {max }}, \boldsymbol{n m}$ & Intensity at maximum \\
\hline sCT & 0 & 640 & 3.3 \\
& 1 & 637 & 1.9 \\
& 7 & 641 & 3.7 \\
QPa & 0 & 626 & 196 \\
& 1 & 628 & 171 \\
& 7 & 627 & 172 \\
Complex & 0 & 620 & 181 \\
& 1 & 620 & 173 \\
& 7 & 620 & 175 \\
\hline
\end{tabular}

\subsubsection{TEM}

sCT did not form any discernable structures in either buffer when analysed using TEM (data not shown). The diameters of the sCT-QPa complexes at the two different $\mathrm{pH}$ values were approximately $120 \mathrm{~nm}$ and the morphology of both complexes was similar; both appeared to be vesicular structures with aqueous cores (Fig. 4). The thickness of the vesicle was around 22nm, thicker than the typically reported bilayer membrane thickness of $11 \mathrm{~nm}$ [24], indicating the membrane might consist of more than one bilayer. 


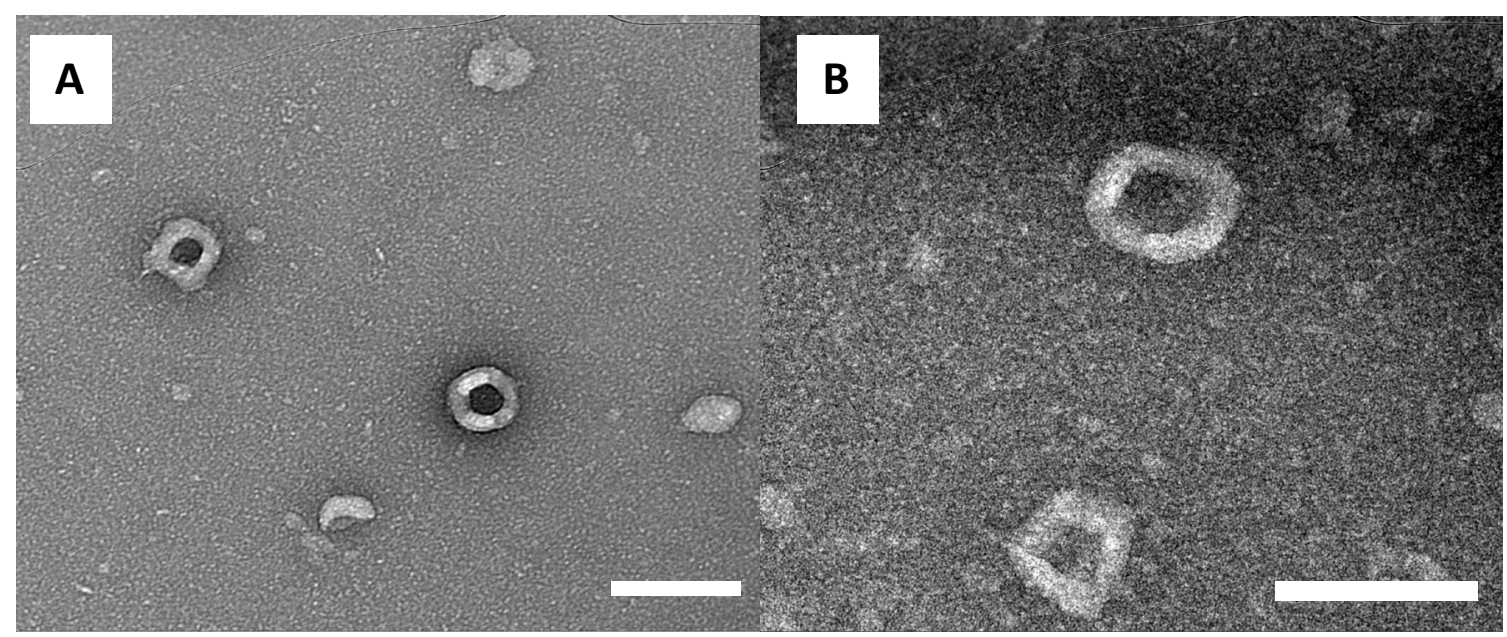

Fig. 4. Negatively-stained TEM images of freshly-prepared $\mathrm{sCT}-\mathrm{QPa}$ complexes $\left(2: 1 \mathrm{mg} \mathrm{mL}^{-1}\right)$ in $\mathrm{pH} 5$ buffer (A) or $\mathrm{pH} 7.4$ buffer (B). Scale bar $=200 \mathrm{~nm}$.

\subsection{Intracellular cAMP induced by $s C T$ and $s C T-Q P a$ on T47D cells}

Intracellular cAMP activities in T47D cells were monitored to determine the bioactivity of sCT in freshly prepared complexes. Samples increased the intracellular cAMP in a concentration-dependent manner (Fig. 5A). Complexes in both buffers as well as free sCT were bioactive and maximal efficacy was achieved by each of the three groups. The $\mathrm{EC}_{50}$ values were (nM): free sCT $(0.73 \pm 0.1)$, sCT-QPa, $\mathrm{pH} 7.4(3.3 \pm 0.1)$ and $\mathrm{sCT}-\mathrm{QPa}$ at $\mathrm{pH} 5.0(7.9 \pm 0.1)$. Although the $\mathrm{EC}_{50}$ values suggested that the presence of $\mathrm{QPa}$ in the complexes at $\mathrm{pH} 7.4$ and $\mathrm{pH}$ 5.0 caused reductions in respective potency compared to free $\mathrm{sCT}$, these $\mathrm{nM}$ values were still very acceptable. The sCT bioactivity of the freshly prepared samples at day 0 and at day 7 following storage at room temperature in the dark was also determined (Fig 5B). Irrespective of the buffers used, free $\mathrm{sCT}$ was completely degraded at day 7 , but there was still significant bioactivity in the complexes stored for 7 days. 


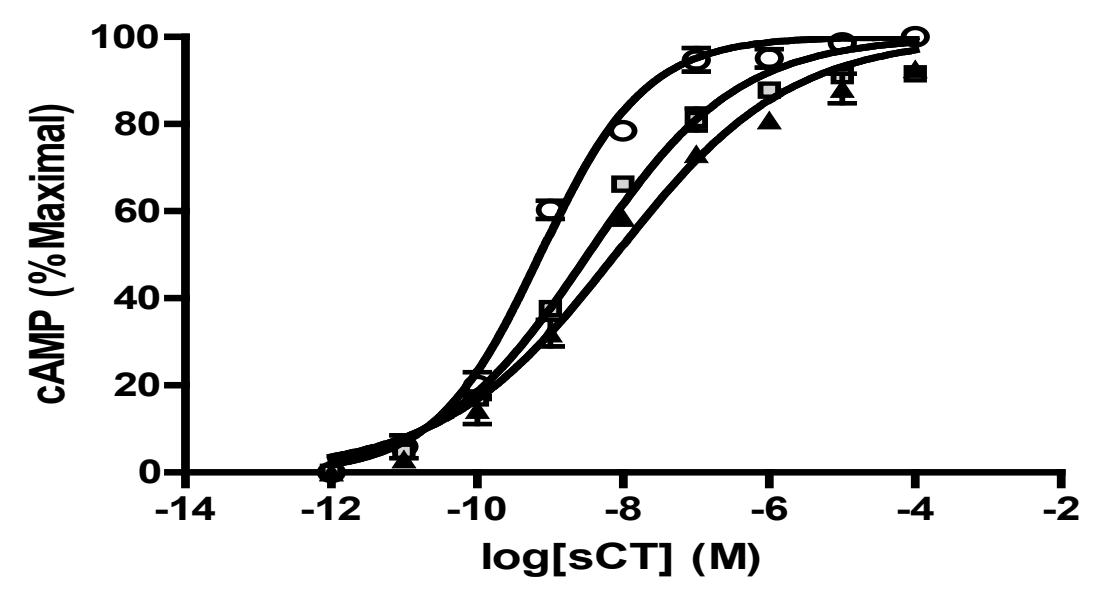

B

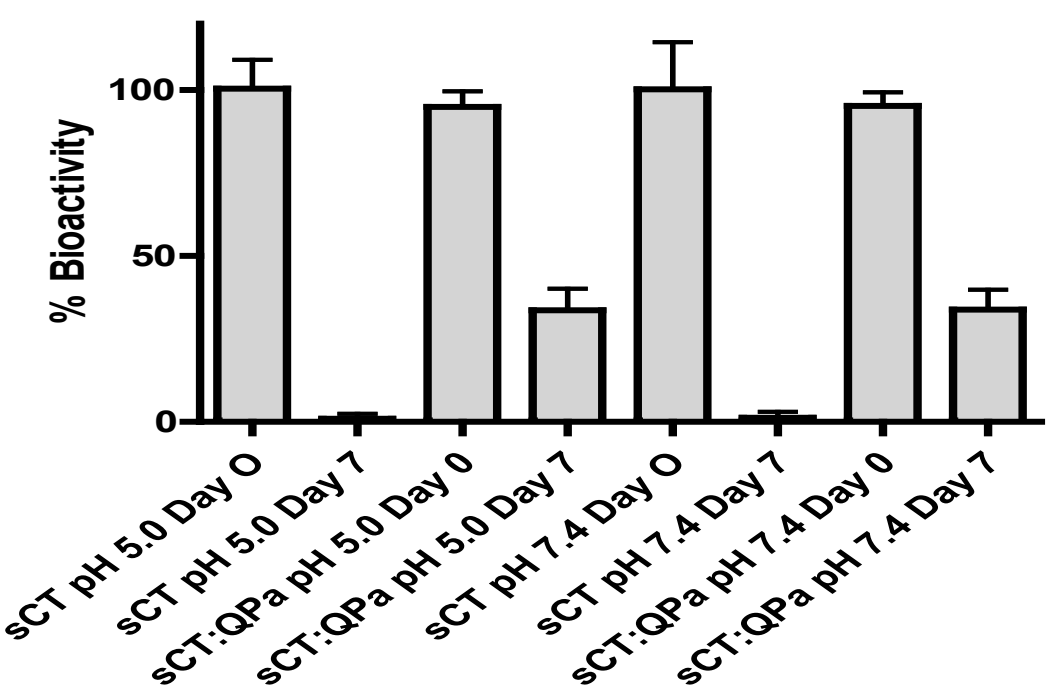

Fig. 5. A. Concentration-response curves for $\mathrm{sCT}$ and $\mathrm{SCT}-\mathrm{QPa}$ stimulation of cAMP production in T47D cells. sCT (०), sCT-QPa, pH 7.4 (口), sCT-QPa, pH 5.0 ( $\mathbf{\Delta}$ ). B. cAMP production by sCT and sCT-QPa complexes at $\mathrm{pH} 7.4$ and $\mathrm{pH} 5.0$ on Day 0 and Day 7 on T47D cells. The concentration of $\mathrm{sCT}$ was $10 \mu \mathrm{M}$ in each preparation. ( $\mathrm{N}=3$ in each case).

\subsection{Intestinal enzyme metabolism}

Freshly prepared free sCT and sCT-containing complexes were incubated with three intestinal enzymes and the intracellular cAMP activities in T47D cells were determined. Free 
sCT was rapidly degraded by chymotrypsin, elastase and trypsin. There was only $3 \%$ activity remaining in the free $\mathrm{sCT}$ when exposed to all three enzymes combined at $30 \mathrm{~min}$ (Fig 6). At both $\mathrm{pH}$ values, the $\mathrm{sCT}$ in the complexes was significantly protected from degradation by the enzymes.

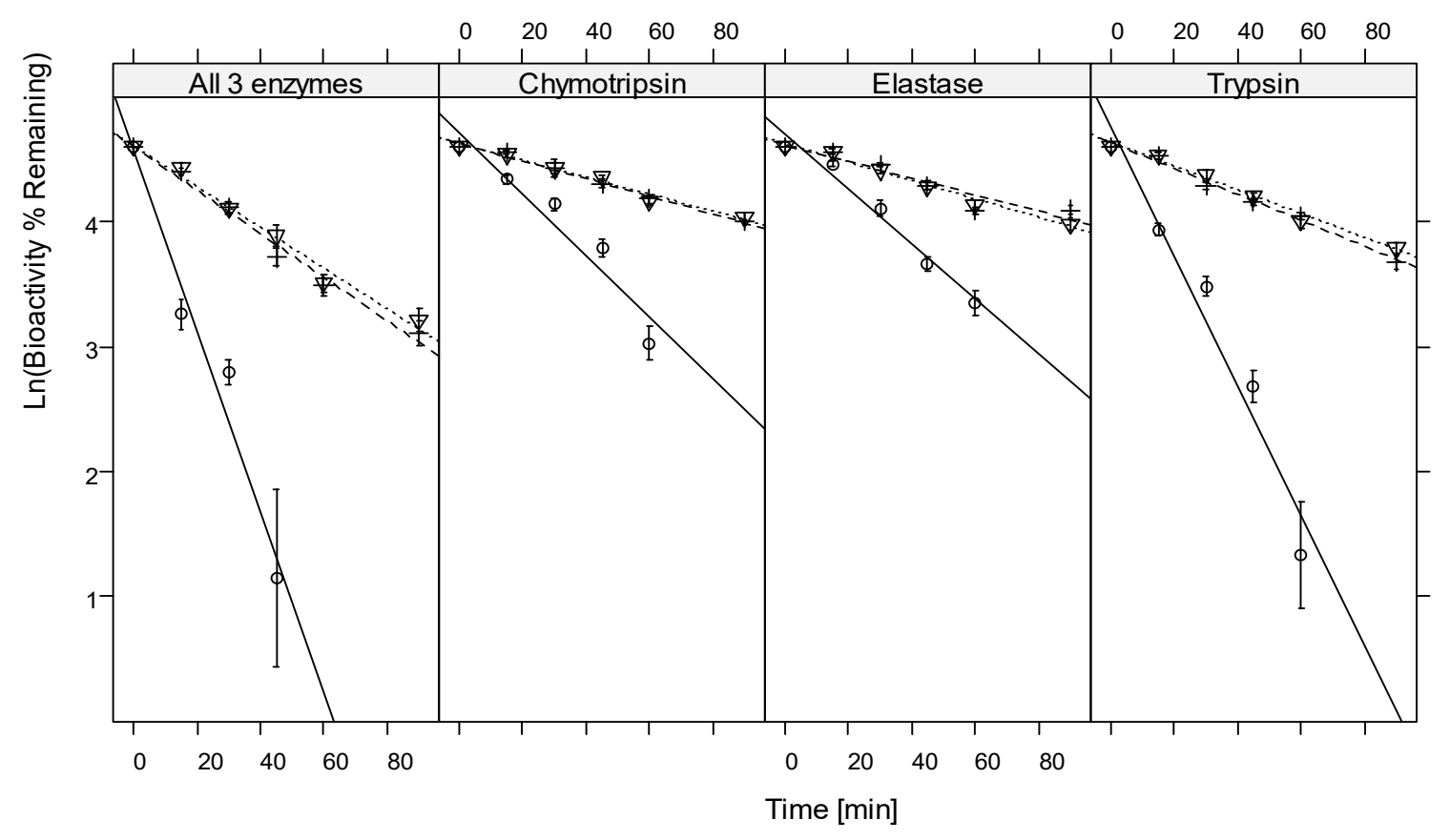

Figure 6: Degradation profiles of sCT, sCT-QPa ( $\mathrm{pH}$ 5.0) and $\mathrm{sCT}-\mathrm{QPa}(\mathrm{pH} 7.4)$ when incubated with three intestinal enzymes. Samples were applied onto T47D cells and cyclic AMP measured. sCT (०), sCT-QPa, pH 7.4 ( $\nabla)$, sCT-QPa, pH $5.0(+)$. Curve fitting was based on first order kinetics $(\mathrm{N}=3$ in each case). 


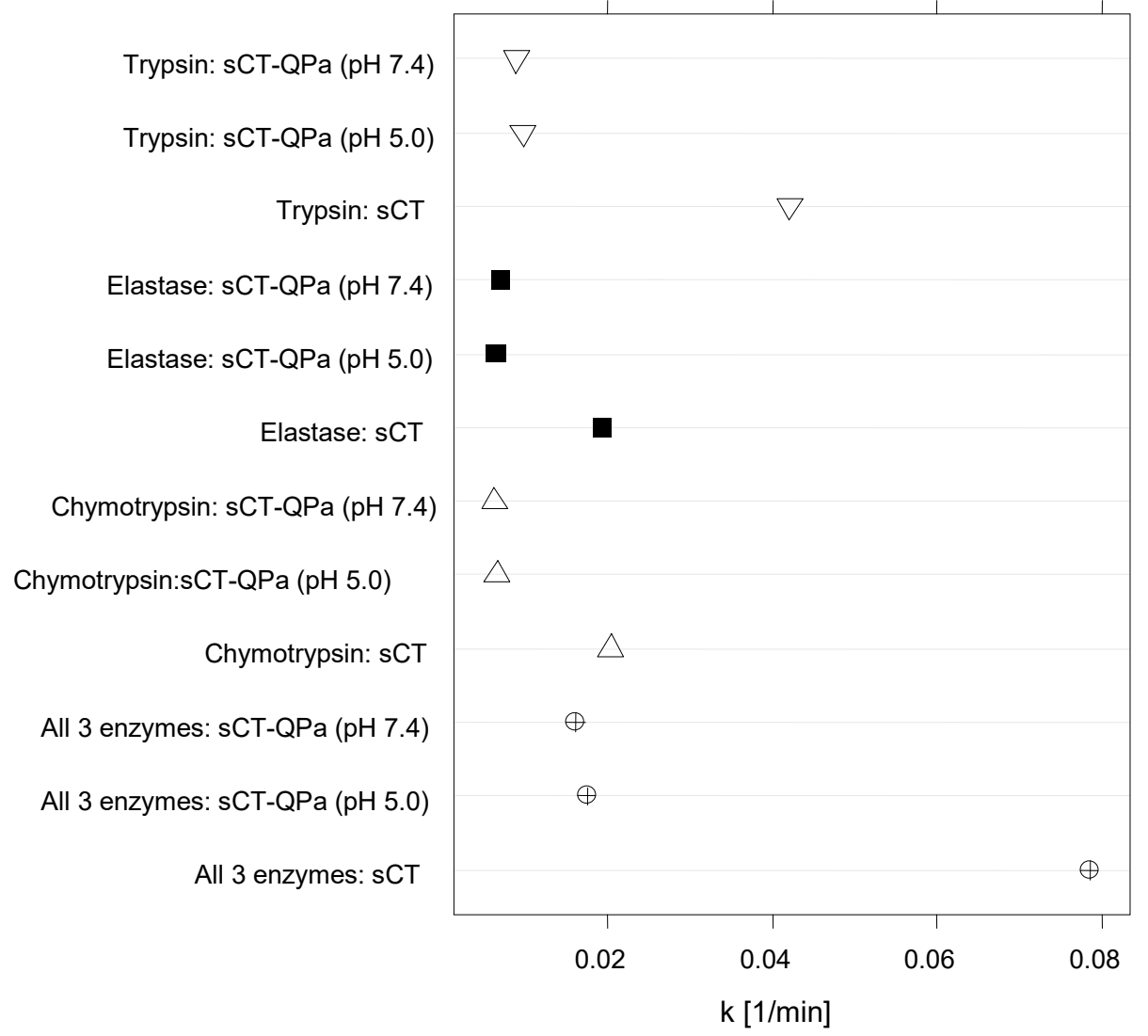

Fig. 7 Comparison of degradation rates of $\mathrm{sCT}$, sCT-QPa (pH 5.0) and sCT-QPa (pH 7.4) in the presence of serine proteases, as determined by cyclic AMP measurements in T47D cells.

$63.0 \pm 0.1 \%, 57.0 \pm 0.1 \%$ and $41.9 \pm 0.02 \%$ bioactivity remained following sCT-QPa exposure to chymotrypsin, elastase and trypsin respectively for $90 \mathrm{~min}$, pooled data at both $\mathrm{pH}$ values. QPa presence in both formulations reduced the degradation rate of sCT by 5-fold when all three enzymes were combined compared to free sCT (Fig 7) $(\mathrm{p}<0.005)$.

\subsection{Hypocalcaemia induced by $s C T-Q P a$ complexes in rats}

The biological effects of sCT-QPa complexes at $\mathrm{pH} 5.0$ and $\mathrm{pH} 7.4$ were evaluated by induction of hypocalcaemic response in rats following i.v. and i.j. administration. At sCT 
equivalent doses following i.v. administration, the total percentage calcium decrease induced by $\mathrm{sCT}(\mathrm{pH} 5.0)$ and $\mathrm{sCT}-\mathrm{QPa}(\mathrm{pH} 5.0)$ were similar, $23.1 \pm 2.3 \%$ and $22.9 \pm 3.8 \%$ at $120 \mathrm{~min}$ respectively (Fig. 8A). $\mathrm{sCT}(\mathrm{pH} 7.4)$ and $\mathrm{sCT}-\mathrm{QPa}(\mathrm{pH} 7.4)$ induced decreases of $30.0 \pm 2 \%$ and $29.3 \pm 1.7 \%$ respectively over the same period. There were no differences between any of the sCT preparations. $\mathrm{QPa}(\mathrm{pH} 5.0$ and 7.4) was without effect over the period following i.v. administration. A very similar set of data was obtained following i.j. administration (Fig. 8B). The sCT-QPa complexes were bioactive in vivo with no loss of activity compared to free sCT. Intestinally instilled complexes retained the capacity to cross the epithelium.
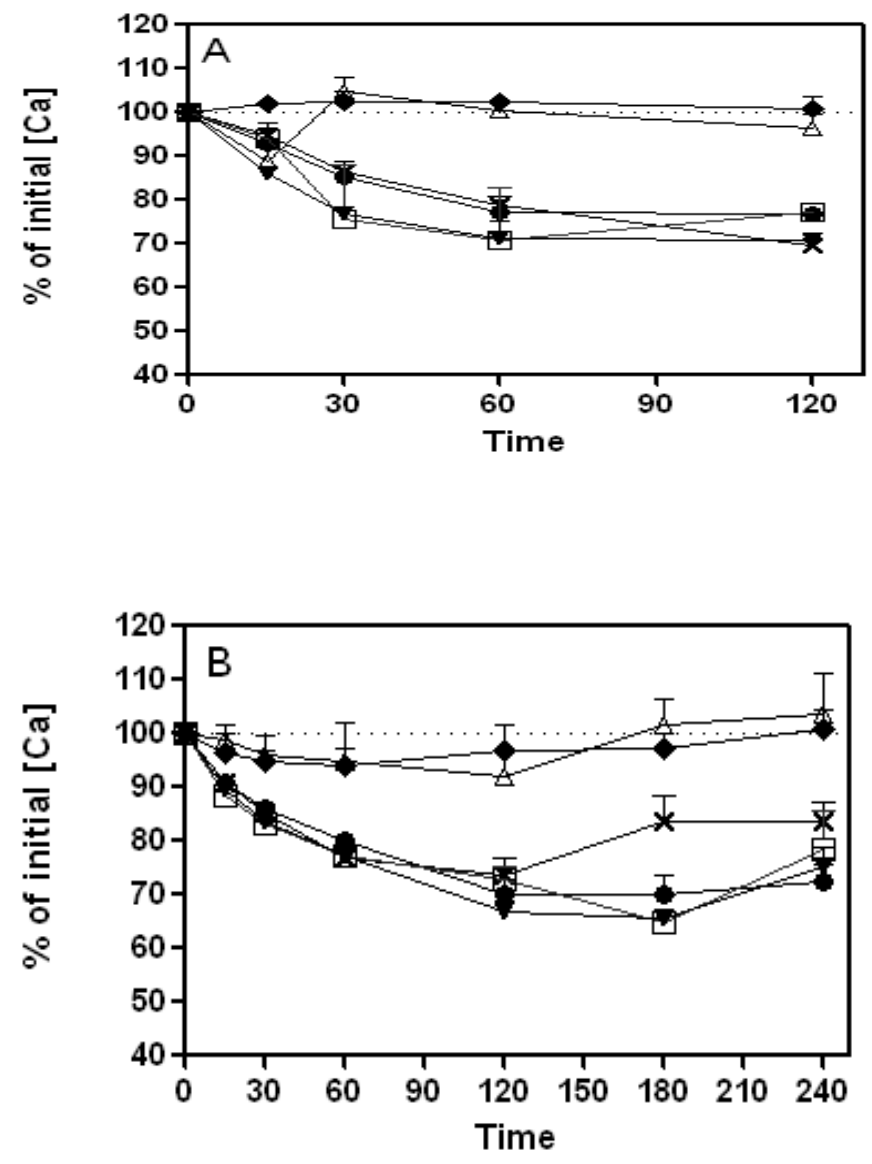

Fig.8. A. Plasma calcium levels in rat serum after i.v. administration of QPa, pH 5.0 $(\Delta)$, QPa, pH $7.4(\bullet), \mathrm{sCT}, \mathrm{pH} 5.0(\bullet), \mathrm{sCT}, \mathrm{pH} 7.4(\mathrm{x}), \mathrm{sCT}-\mathrm{QPa}, \mathrm{pH} 5.0(\square)$, and sCT-QPa, pH $7.4(\boldsymbol{\nabla})$. Mean $\pm \operatorname{SEM}(n=3)$. B.i.j administration: groups and symbols as in $A$. $(\mathrm{N}=3-4)$. 


\section{Discussion}

There are four commercially available formulations of sCT; the recommended dose for the daily nasal spray to treat post-menopausal osteoporosis is 200 I.U, while 100 I. U. are administered every other day for injections. sCT is normally formulated in acidic media consisting of acetate, hydrochloric acid or citric acid buffers, as SCT is more stable in acid pH than at $\mathrm{pH} 7.4$ [25]. Since the isoelectric point of $\mathrm{sCT}$ is 10.2 , it will be positively-charged at acidic and physiological $\mathrm{pH}$ values [26]. We looked at the ability of the cationic amphiphilic polyelectrolyte $(\mathrm{QPa})$ to complex with $\mathrm{sCT}$ at $\mathrm{pH} 5.0$ and 7.4 and assessed the impact of the polymer on sCT's physical stability, resistance in vitro enzymatic degradation and in vitro and in vivo bioactivity. We did not expect complexation to occur easily in view of the likely potential for electrostatic repulsion.

Polyamines are effective non-cytotoxic permeation enhancers across intestinal epithelia and they can open epithelial tight junctions in vitro [27]. For example, spermine formulated in polyacrylic acid polyelectrolyte complexes improved the oral absorption of sCT in rats following intra-duodenal administration [28]. It is possible that QPa may also act as an epithelial permeation enhancer and this may be of benefit in addition to peptidase inhibition. Initial studies suggest that it also reversibly opens tight junctions in Caco-2 monolayers (unpublished data). We have previously illustrated the potential use of amphiphilic polyamines based on PAA for oral insulin delivery $[11,12]$. The attachment of palmitoyl chains and the addition of quaternary ammonium moieties resulted in an 11-fold reduction in cytotoxicity of QPa compared to its parent molecule (PAA), Although sCT is positively charged, complexation was still achieved with QPa in the current study, resulting in a narrow particle size distribution with a hydrodynamic diameter of approximately $200 \mathrm{~nm}$. Unlike other polyelectrolyte complexes, 
which require centrifugation to obtain the nano-complexes, freshly prepared $\mathrm{sCT}-\mathrm{QPa}$ complexes were clear in appearance, confirmed by the low absorbance UV reading and the absence of pellets after centrifugation. The differences observed between the DSC thermal profiles of free $\mathrm{sCT}$ and complexes in both $\mathrm{pHs}$ suggesting the presence of physical-chemical interaction between $\mathrm{SCT}$ and $\mathrm{QPa}$, which correlated well with other polyelectrolyte-protein complexes $[11,19]$. The assessment of the physical stability of the complex was based on data from the combination of size and zeta potential measurements, turbidity, as well as intrinsic and extrinsic fluorescence. Overall, QPa complexation had a positive effect on the physical stability of sCT. Unstable formulations would have resulted in an increase in particle size, turbidity and peptide aggregation. While free $\mathrm{sCT}$ was more physically stable for longer periods at $\mathrm{pH} 5.0$ than $\mathrm{pH} 7.4$ according to the tyrosine fluorescence study, the in vitro bioassay suggested little difference at the level of function where both very equally efficacious at Day 0 and inefficacious at Day 7. Although sCT-QPa ( $\mathrm{pH}$ 7.4) complexes showed some signs of instability at 7 days, the changes detected by these studies were considerably less than the deterioration in free $\mathrm{SCT}(\mathrm{pH}$ 7.4) over the same period.

Nile red can detect hydrophobic micro-domains in aqueous solutions formed by amphiphilic polymers [29]. The blue shift in the maximum emission wavelength observed with QPa correlates with the results with alkylated poly(L-lysine) citramide [29]. Thus, it partitions from the aqueous environment into the hydrophobic domains formed by the palmitoyl grafts on QPa. Importantly, a similar blue shift was also observed in free $\mathrm{sCT}(\mathrm{pH} 5.0)$, indicating the presence of hydrophobic domains on the peptide. Finally, when sCT was complexed with QPa, the further reduction in the maximum emission wavelength suggests that likely changes in the conformation of the complex exposed additional hydrophobic surfaces for dye binding. From 
TEM images, it would appear that the polymer and $\mathrm{sCT}$ interact and alter the conformation of both. QPa normally forms discrete, dense nanoparticles, either alone or when complexed with insulin [10-12]. When complexed with $\mathrm{sCT}$ however, there was an unusual alteration in the conformation, resulting in a bilayered vesicular structure. In sum, sCT seems to undergo unfolding in the presence of $\mathrm{QPa}$, which results in exposure of hydrophobic domains. Assuming that these domains intercalate between the palmitoyl chains of QPa, such interactions may lead to increased backbone flexibility and the subsequent production of liposome-like bilayer vesicles $[30,31]$.

Amphiphilic polyelectrolytes for peptide and protein delivery have not been widely studied to date. Unlike complexation between proteins and polyelectrolytes based on electrostatic interaction, association of proteins with amphiphilic polyelectrolytes in water can be affected by non-covalent hydrophobic Van der Waals associations and hydrogen bonds. Even though QPa and $\mathrm{sCT}$ are both positively charged, complexation still took place. Pockets of anionic charges on the surface of sCT may interact with $\mathrm{QPa}$, as shown for other peptide-polymer complexes [32]. Still, sCT-QPa PEC had consistent and narrowly distributed zeta potentials similar to QPa alone, inferring that the predominant interaction was indeed due to hydrophobic associations or hydrogen bonds. Others have successfully used co-polymers consisting of a hydrophobic polystyrene backbone grafted with poly-N-isopropylacrylamide (PNIPAAm) and polyvinylamine (PVAm) for sCT delivery [9]. The presence of non-ionic PNIPAAm and cationic PVAm in the nanocomplexes resulted in increased oral biovailability, which may have been due to hydrogen bonding between $\mathrm{sCT}$ and macro-monomer chains. Similarly, formation of complexes composed of serum albumin and negatively-charged polyacrylates modified with alkyl chains has been achieved [33]. The complexation was dependent in part on the number of 
alkyl chains, implying that hydrophobic association is indeed an especially important parameter in the complexation process when amphiphilic polyelectrolytes and the protein have the same overall surface charge.

Use of conventional delivery systems including poly(D,L lactide-co-glycolide) microparticles might lead to reduction of sCT bioactivity and even induce immunogenicity due to chemical modifications such as acylation and also $\mathrm{pH}$ changes in the particulates [34]. Therefore, it is important to assess the bioactivity of sCT in the QPa complexes. There is excellent correlation between the in vitro bioassay and HPLC analysis for $\mathrm{SCT}$ and polymeric derivatives [22] and hence in this study, we relied on determination of the bioactivity of SCT on T47D cells, since HPLC does not detect loss of function. At both $\mathrm{pH}$ values, the sCT-QPa complexes had the same excellent efficacy and just a slight loss in potency compared to free sCT. $\mathrm{sCT}$ adopts a random coil structure, but has a relatively undeveloped secondary structure and no tertiary conformation [35], but despite likely changes in secondary conformation in the nanocomplex, it is still able to maintain its in vitro biological activity. The sCT bioactivities were also evaluated on the day 7 formulations, which were kept in the dark at room temperature. Free $\mathrm{sCT}$ was completely degraded by day 7 , while both complexes maintained significantly higher bioactivity than free $\mathrm{sCT}$ at both $\mathrm{pH} 5.0$ and $\mathrm{pH}$ 7.4. In aqueous solutions $\mathrm{sCT}$ normally undergoes rapid degradation including disulphide breakage and subsequent trisulphide bond formation, as well as dimerization via covalent bond and backbone hydrolysis [36]. Complexation of sCT with $\mathrm{QPa}$ reduced the degradation process and at least $40 \%$ of the activity was retained after 7 days. Although the physical stability studies indicated that day 7 complexes at $\mathrm{pH} 7.4$ were less stable than those at $\mathrm{pH} 5.0$, it was somewhat surprising to find that both complexes retained similar in vitro $\mathrm{sCT}$ bioactivity. The secondary structure of $\mathrm{SCT}$ is based on 
an $\alpha$-helix and $\beta$-sheet [37]. Their presence in sCT may in part promote fibril formation and aggregation in aqueous solutions, ultimately leading to physical instability $[34,36]$, although this is thought to not to occur nearly as readily with $\mathrm{SCT}$ as for human $\mathrm{CT}$. Despite this possibility, the $\mathrm{sCT}$ in the complex formed in either $\mathrm{pH}$ buffer was still able to interact with calcitonin receptors to elicit the biological response.

Proteins and peptides undergo extensive enzymatic degradation in the intestine, serum and liver . Complexation between $\mathrm{sCT}$ and $\mathrm{QPa}$ has resulted in significant protection of sCT from the major endopeptidases at concentrations present in the small intestine. When sCT was conjugated to either linear PEG or to a novel comb-shaped Poly(PEG)methacrylate polymer, almost identical protection was noted as in the current study [22]. Most likely, the complexed QPa shielded the sCT and this steric hindrance mechanism (similar to the umbrella-like effect postulated for poly(PEG)methacrylate) protected sCT from peptidase attack. It would not be correct however, to assume that generalizations can be made in respect of polymer protection, since complexation between QPa and insulin resulted in increased peptide degradation by chymotrypsin compared to that seen with free insulin [12]. This demonstrates that whether amphiphilic polyelectrolytes can protect proteins against enzymatic degradation is largely dependent on the protein, its surface charge and its secondary and tertiary structure. Insulin is a globular protein with a tertiary conformation and complexation resulted in the unfolding of the protein exposing the chymotrypsin target sites. It is possible that absence of tertiary conformation in $\mathrm{SCT}$ resulted in minimal unfolding, and therefore the shielding effect of QPa resulted in protection against peptidases. In vivo biological efficacy of sCT-QPa complexes were assessed in rats and irrespective of the type of buffers used, both formulations had similar hypocalcaemic effects compared to free $\mathrm{sCT}$, consistent with our in vitro bioactivity assays. 
Intra-jejunal administration revealed that the complexes retained bioactivity, although we did not ascertain whether they remain intact during epithelial transport. This is likely however, since the complexes protected $\mathrm{sCT}$ in a range of peptidase containing buffers over significant time periods. Future work will further investigate the potential of these complexes by administering these complexes by single pass rat intestinal perfusion and ultimately by oral gavage of coated soliddose formulations.

\section{Conclusions}

Despite similar overall surface charges, sCT-QPa nano-complexes were spontaneously produced by mixing two aqueous solutions at room temperature without the need for surfactant stabilizers, organic solvents or sonication. Unlike complexation between protein and polyelectrolyte of oppositely charges relying primarily on electrostatic interaction, it is likely that the predominant interaction of $\mathrm{QPa}, \mathrm{sCT}$ was due to hydrophobic associations of palmitoyl chains grafted onto PAA. The complexation resulted in the production of nano-complexes in the region of 200nm which were able to maintain stability physical and biological stability compared to free $\mathrm{sCT}$ in either $\mathrm{pH} 5.0$ or 7.4 buffers. The ability of QPa to protect sCT against intestinal enzymatic degradation and to achieve similar in vivo hypocalcaemic responses as for free $\mathrm{sCT}$ following i.j. administration warrant further investigation to determine its potential as an oral peptide delivery system.

\section{Acknowledgements}


We thank Xuexuan Wang at UCD for carrying out the intravenous injections of the sCT-QPa and for providing the resulting serum calcium data. Supported by Science Foundation Ireland Grant Number 07 SRC/B1154 and Cunningham Trust ACC/KWF/CT07/09. 


\section{References}

[1] H. Morawetz, W. L. Hugues, The interaction of proteins with synthetic polyelectrolytes. I. Complexing of bovine serum albumin. J. Phys. Chem. 56 (1951) 64-69.

[2] D. Fiorentino, A. Gallone, D. Fiocco, G. Palazzo, A. Mallardi, A. Mushroom tyrosinase in polyelectrolyte multilayers as an optical biosensor for o-diphenols. Biosens. Bioelectron. 25 (2010) 2033-2037.

[3] V. Boeris, D. Romanini, B. Farruggia, G. Pico, Purification of chymotrypsin from bovine pancreas using precipitation with a strong anionic polyelectrolyte. Process Biochemistry, 44 (2009) 588-592.

[4] S. Mao, U. Bakowsky, A. T. Jintapattanakit, T. Kissel, Self-assembled polyelectrolyte nanocomplexes between chitosan derivatives and insulin. J. Pharm. Sci. 95 (2006) 1035-1048.

[5] A. Jintapattanakit, V. B. Junyaprasert, S. Mao, J. Sitterberg, U. Bakowsky, T. Kissel, Peroral delivery of insulin using chitosan derivatives: A comparative study of polyelectrolyte nanocomplexes and nanoparticles. Int. J. Pharm. 342 (2007) 240-249.

[6] H. Hu, L. Yu, S. Tan, K. Tu, L-Q Wang, Novel complex hydrogels based on N-carboxyethyl chitosan and quaternized chitosan and their controlled in vitro protein release property. Carbohydrate Res. 345 (2010) 462-468.

[7] V. Boeris, D. Romanini, B. Farruggia, G. Pico, Interaction and complex formation between catalase and cationic polyelectrolytes: Chitosan and Eudragit E100. Int. J. Biological Macromolecules 45 (2009) 103-108.

[8] M. Simon, M. Wittmar, T. Kissel, T. Linn, Insulin-containing nanocomplexes formed by selfassembly from biodegradable amine-modified poly(vinyl alcohol)-graft-poly(L-lactide): Bioavailability and nasal tolerability in rats. Pharm. Res. 22 (2005) 1879-1886. 
[9] S. Sakuma, N. Suzuki, R. Sudo, K. Hiwatari, A. Kishida, M. Akashi, Optimized chemical structure of nanoparticles as carriers for oral delivery of salmon calcitonin. Int. J. Pharm. 239 (2002) 185-195.

[10] C. J. Thompson, C. X. Ding, X. Qu, Z. Yang., I. F. Uchegbu, L. Tetley, W. P. Cheng, The effect of polymer architecture on the nano self-assemblies based on novel comb-shaped amphiphilic poly(allylamine). Colloid Polymer Sci. 286 (2008) 1511-1526.

[11] C. J. Thompson, L. Tetley, I. F. Uchegbu, W. P. Cheng, The complexation between novel comb shaped amphiphilic polyallylamine and insulin - Towards oral insulin delivery. Int. J. Pharm. 376 (2009) 46-55.

[12] C. J. Thompson, L. Tetley L, W.P. Cheng, The influence of polymer architecture on the protective effect of novel comb shaped amphiphilic poly(allylamine) against in vitro enzymatic degradation of insulin-towards oral insulin delivery. Int. J. Pharm. 383 (2010) 216-227.

[13] J. Xia, P. L. Dubin, Y. Kim, B. B. Muhoberac, V. J. Klimkowski V.J., Electrophoretic and quasi-elastic light scattering of soluble protein-polyelectrolyte complexes. J. Physical Chem. 97 (1993) 4528-4534.

[14] S. Sakuma, N. Suzuki, H. Kikuchi, K. Hiwatari, K. Arikawa, A. Kishida, M. Akashi, Oral peptide delivery using nanoparticles composed of novel graft copolymers having hydrophobic backbone and hydrophilic branches. Int. J. Pharm. 149 (1997) 93-106.

[15] C. H. Chesnut 3rd, M. Azria, S. Silverman, M. Engelhardt, M. Olson, L. Mindeholm. Salmon calcitonin: a review of current and future therapeutic indications. Osteoporos. Int. 19 (2008) 479-491.

[16] B-C. Sondergaard, S. H. Madsen, T. Segovia-Silvestre, S. J. Paulsen, T. Christiansen, C. Pedersen, A-C. Bay-Jensen, M. A. Karsdal, Investigation of the direct effects of salmon calcitonin on human chondrocytes, BMC Musculoskeletal Disorders, 11 (2010) 62-71. 
[17] P. Peichl, A. Griesmacher, W. Kumpan, R. Schedl, E. Prosquil, H. Bröll H, Clinical outcome of salmon calcitonin nasal spray treatment in postmenopausal women after total hip arthroplasty. Gerontology, 51 (2005) 242-252.

[18] F. L. Lanza, Gastrointestinal adverse effects of bisphosphonates: etiology, incidence and prevention. Treat Endocrinol. 1 (2002) 37-43.

[19] H. E. Lee, M. J. Lee, C. R. Park, A. Y. Kim, K. H. Chun, H. J. Hwang, D. H. Oh, S. O. Jeon, J. S. Kang, T. S. Jung, G. J. Choi, S. Lee. Preparation and characterization of salmon calcitonin-sodium triphosphate ionic complex for oral delivery. J. Control. Release 143 (2010) 251-257.

[20] M. A. H. Capelle, R. Gurny, T. Arvinte, A high throughput protein formulation platform: case study of salmon calcitonin. Pharm. Res. 26 (2009) 118-128.

[21] S. B. Fowler, S. Poon, R. Muff, F. Chiti, C.M. Dobson, J. Zurdo, Rational design of aggregation-resistant bioactive peptides: re-engineering human calcitonin, Proc. Natl. Acad. Sci. U. S. A. 102 (2005) 10105-10110.

[22] S. M. Ryan, X. Wang, G. Mantovani, C. T. Sayers, D. M. Haddleton, D. J. Brayden, Conjugation of salmon calcitonin to a combed-shaped end functionalized poly(poly(ethylene glycol) methyl ether methacrylate) yields a bioactive stable conjugate. J. Control. Release 135, (2009) 51-59.

[23]. S. Maher, X. Wang, V. Bzik, S. McClean, D. J. Brayden, Evaluation of intestinal absorption and mucosal toxicity using two promoters. II. Rat instillation and perfusion studies. European J. Pharm. Sci. 38 (2009) 301-311.

[24] T. Janas, T. Janas, K. Walinska, Properties of hexadecaprenyl monophosphate /dioleoylphosphatidylcholine vesicular lipid bilayers. J. Membr. Biol. 177 (2000) 259-271. 
[25] Y. H. Lee, B. A. Perry, S. Labruno, H. S. Lee, W. Stern, L. M. Falzone, P. J. Sinko PJ. Impact of regional intestinal $\mathrm{pH}$ modulation on absorption of peptide drugs: oral absorption studies of salmon calcitonin in beagle dogs. Pharm. Res. 16 (1999) 1233-1239.

[26] T. Tsai, R. C. Mehta, P. P. DeLuca, Adsorption of peptides to poly(D,L-lactide-coglycolide): 2. Effect of solution properties on the adsorption. Int. J. Pharm. 127 (1996) 43-52.

[27] B. J. Aungst, Intestinal permeation enhancers. J. Pharm. Sci. 89, (2000) 429-442.

[28] A. Makhlof, M. Werle, Y.Tozuka, H. Takeuchi, A mucoadhesive nanoparticulate system for the simultaneous delivery of macromolecules and permeation enhancers to the intestinal mucosa. J. Control. Release (2010) PMID: 20138935.

[29] S. Gautier, M. Boustta, M. Vert, Alkylated poly(L-lysine citramide) as models to investigate the ability of amphiphilic macromolecular drug carriers to physically entrap lipophilic compounds in aqueous media. J. Control. Release 60 (1999) 235-427.

[30] W. Wang, L. Tetley, I. F. Uchegbu, I.F, The level of hydrophobic substitution and the molecular weight of amphiphilic poly-lysine-based polymers strongly affects their assembly into polymeric bilayer vesicles. J. Colloid Interface Sci. 237 (2001) 200-207.

[31] W. Wang, X. Z. Qu, A. I Gray, L. Tetley, I. F. Uchegbu, Self assembly of cetyl linear polyethylenimine to give micelles, vesicles and dense nanoparticles. Macromolecules 37 (2004) 9114-9122.

[32] J. M. Park, B. Muhoberac, P. L. Dubin, J. Xia, Effects of protein charge heterogeneity in protein-polyelectrolyte complexation. Macromolecules 25 (1992) 290-295.

[33] I. Porcar, P. Gareil, C. Tribet, Formation of complexes between protein particles and long amphiphilic polymers: binding isotherms versus size and surface of particles. J. Physical Chem. B. 102 (1998)7906-7909. 
[34] A. Lucke, J. Kiermaier, A. Gopferich, Peptide acylation by poly(alpha-hydroxy esters) Pharm. Res. 19 (2002) 175-181.

[35] Y. Tang, J. Singh, Thermosensitive drug delivery system of salmon calcitonin: in vitro release, in vivo absorption, bioactivity and therapeutic efficacies. Pharm. Res. 27 (2009) 272284.

[36] V. Windisch, F. Deluccia, L. Duhau, F. Herman, J. J. Mencel, S-Y. Tang, M. Vuilhorgne, Degradation pathways of salmon calcitonin in aqueous solution. J. Pharm. Sci. 86 (1997) 359364.

[37] S. Seyferth, G. Lee, Structural studies of EDTA-induced fibrillation of salmon calcitonin. Pharm. Res. 20 (2003) 73-80. 